\title{
The mGluR6 5' Upstream Transgene Sequence Directs a Cell- Specific and Developmentally Regulated Expression in Retinal Rod and ON-Type Cone Bipolar Cells
}

\author{
Yoshiki Ueda, ${ }^{1}$ Hideki Iwakabe, ${ }^{1}$ Masayuki Masu, ${ }^{1}$ Misao Suzuki, ${ }^{2}$ and Shigetada Nakanishi ${ }^{1}$ \\ ${ }^{1}$ Department of Biological Sciences, Kyoto University Faculty of Medicine, Kyoto 606-01, Japan, and 2Institute of \\ Molecular Embryology and Genetics, Kumamoto University Medical School, Kumamoto 862, Japan
}

We generated transgenic mice, using 9.5 kilobase pairs of the $5^{\prime}$ upstream sequence from the mouse metabotropic glutamate receptor subtype 6 (mGluR6) gene fused to the $\beta$-galactosidase (lac $Z$ ) reporter gene, and investigated the promoter function of the cell-specific and developmentally regulated expression of mGluR6. Most of the independent transgenic lines commonly showed the lac $Z$ expression in the defined cell layers of the retina, and four transgenic lines were characterized in detail for cell-specific lac $Z$ expression patterns by $X$-gal staining and lacZ immunostaining. The lacZ-expressing retinal cells were classified into two cell types. One cell type was identified as rod bipolar cells on the basis of colocalization of protein kinase $\mathrm{C}$ (PKC) immunoreactivity and morphological criteria. The other cell type was PKC-immunonegative and resided at the cell layers corresponding precisely to ON-type cone bipolar cells. The latter bipolar cells were found to exist as a large cell population comparable to rod bipolar cells. This observation was confirmed by coimmunostaining of dissociated retinal cells with the lacZ and PKC antibodies. The ontogeny analysis indicated that the lac $Z$ expression completely agrees with a temporal expression pattern of mGluR6 during retinal development. This study demonstrates that the mGluR6 5' upstream genomic sequence is capable of directing a cell-specific and developmentally regulated expression of mGluR6 in ON-type bipolar cells and supports the view that mGluR6 is responsible for ON responses in both the rod and cone systems.

Key words: transgenic mouse; metabotropic glutamate receptor; $\beta$-galactosidase; retinal bipolar cells; immunostaining
Visual information is segregated into parallel ON and OFF pathways at retinal bipolar cells (Miller and Slaughter, 1986; Dowling, 1987; Daw et al., 1990; Schiller, 1992; Nakanishi, 1995). Photoreceptors hyperpolarize by light exposure and reduce the release of excitatory glutamate transmitter. In the cone system ON-type bipolar cells, in turn, depolarize, whereas OFF-type bipolar cells hyperpolarize. The reverse reaction occurs when light exposure is terminated. ON-type and OFF-type bipolar cells form synapses with $\mathrm{ON}$-center and OFF-center ganglion cells, respectively, and transmit the respective signals to the ON and OFF pathways. In the rod system all bipolar cells represent the ON-type and form synapses with a subset of amacrine cells. The amacrine cells, in turn, connect with the ON-type cone bipolar cells via gap junctions and with the OFF-type cone bipolar and OFF-center ganglion cells via inhibitory synapses. Thus, in both systems the ON and OFF responses are evoked in response to the onset and termination of light, respectively.

Electrophysiological evidence indicated that ON-type bipolar cells have a specific metabotropic glutamate receptor (mGluR) that activates cGMP phosphodiesterase via a G-protein (Nawy and Jahr, 1990; Shiells and Falk, 1990). This receptor is activated selectively by a glutamate analog, L-2-amino-4-phosphonobutyrate (L-AP4)

Received Dec. 20, 1996; revised Feb. 7, 1997; accepted Feb. 11, 1997.

This work was supported in part by research grants from the Ministry of Education, Science and Culture of Japan, the Ministry of Health and Welfare of Japan, the Uehara Memorial Foundation, and the Sankyo Foundation. Y.U. was supported by a fellowship of the Japan Society for Promotion of Science.

Correspondence should be addressed to Dr. Shigetada Nakanishi, Department of Biological Sciences, Kyoto University Faculty of Medicine, Yoshida, Sakyo-ku, Kyoto 606-01, Japan.

Copyright (C) 1997 Society for Neuroscience $0270-6474 / 97 / 173014-10 \$ 05.00 / 0$
(Slaughter and Miller, 1981), which decreases intracellular cGMP concentrations and leads to the closure of cGMP-gated cation channels, thus hyperpolarizing ON-type bipolar cells (Nawy and Jahr, 1990, 1991; Shiells and Falk, 1990; Yamashita and Wässle, 1991; de la Villa et al., 1995). In accordance with the electrophysiological studies, the molecularly cloned mGluR6 is expressed restrictedly in the bipolar cell layer and responds potently to L-AP4 (Nakajima et al., 1993). Furthermore, mGluR6 is confined to the postsynaptic site of rod bipolar cells (Nomura et al., 1994), and gene targeting of mGluR6 results in a loss of ON responses to light stimulus but unchanged OFF responses to dark stimulus (Masu et al., 1995). Thus, mGluR6 is responsible for synaptic transmission from photoreceptors to ON-type bipolar cells (Shiells, 1994; Masu et al., 1995; Nakanishi, 1995).

The characteristic expression pattern of mGluR6 in retinal bipolar cells raises an interesting question regarding the regulatory sequence and mechanism that determine a cell type-specific and developmentally regulated expression of the mGluR6 gene. In addition, although the role of mGluR6 in postsynaptic transmission to rod bipolar cells had been well established (Shiells, 1994; Nakanishi, 1995), the involvement of mGluR6 in ON responses in cone bipolar cells still was not conclusive (Masu et al., 1995; Iwakabe et al., 1997). To address these questions, we generated transgenic mice by using the $5^{\prime}$ flanking mouse mGluR6 sequence fused to the $\beta$-galactosidase (lacZ) reporter gene. The present studies have indicated that the upstream mGluR6 genomic sequence directs, temporally and spatially, the lac $Z$ expression in retinal ON-type bipolar cells in accurate accordance with the mGluR6 expression pattern. 


\section{MATERIALS AND METHODS}

Plasmid construction. We cloned and mapped the mouse genomic DNAs containing the mGluR6 gene from a mouse genomic library prepared from $129 / \mathrm{SvJ}$ mice DNA (Stratagene, La Jolla, CA) by hybridization with the 665 base pair (bp) DraII fragment of the rat mGluR6 cDNA (Nakajima et al., 1993). The 9.5 kilobase pair (kbp) SphI-NaeI fragment that covers the mGluR6 5' upstream genomic sequence, starting at $49 \mathrm{bp}$ upstream from the translation initiation site, was isolated from one of the clones and inserted into the SalI and NaeI sites of pBluescriptII KS (Stratagene) after a linker replacement of the 5' SphI site with the SalI site. The genomic sequence that covers the translation initiation site of mGluR6 and its upstream sequence was determined by dideoxy chain termination. The 4285 bp HindIII-Pst I fragment was isolated from plasmid pCH110 (Hall et al., 1983). This fragment possesses the Escherichia coli gpt gene fragment containing its translation initiation site, the $E$. coli trpS gene fragment, the lac $Z$ gene encoding $\beta$-galactosidase from amino acid position 9 , and a polyadenylation signal derived from the SV40 early gene. The 717 bp PstIBamHI fragment encoding the SV40 splicing and polyadenylation signals was isolated from pCDM-8 (Seed, 1987) and fused to the above HindIII-PstI fragment at the PstI site, and the resultant fused gene was inserted into pBluescriptII KS. The mGluR6 upstream region was extracted from the above recombinant plasmid by digestion with $\mathrm{XhoI}$ and NaeI, and this fragment was inserted into the plasmid carrying the lacZ gene, using the XhoI and blunted HindIII sites. The final fusion gene in pBluescriptII KS was called MG6-Z (see Fig. $1 A$ ).

Generation of transgenic animals. The MG6-Z gene was extracted from the recombinant plasmid by digestion with SalI and SacII; the SalI-SacII fragment was fractionated by electrophoresis on a $0.5 \%$ low-meltingpoint agarose and purified by silica matrix (Glassmilk, Bio 101, La Jolla, CA). The DNA fragment $(30 \mu \mathrm{g} / \mathrm{ml})$ eluted in $1 \mathrm{~mm}$ Tris- $\mathrm{Cl}$ and $0.1 \mathrm{~mm}$ EDTA, $\mathrm{pH}$ 8.0, was microinjected into pronuclei of BDF1 (C57BL/6J $\times$ DBA/2J) fertilized one-cell embryos. Injected embryos were transplanted into the oviducts of pseudopregnant female mice. One hundred and twenty-four founder mice were produced. Integration of the lac $Z$ gene was analyzed by Southern blot hybridization of BamHI-digested tail DNAs with a radiolabeled $C l a \mathrm{I}-\mathrm{Sac}$ I fragment of the $l a c Z$ gene. Thirteen of 24 transgenic lines that were $l a c Z$ gene-positive passed their transgenes onto their offspring. Total RNA was extracted by the acid guanidiniumphenol-chloroform method (Isogen, Nippon Gene, Tokyo, Japan), and poly $\left(\mathrm{A}^{+}\right)$RNA was purified by oligo $(\mathrm{dT})_{30}$-conjugated latex particles (Oligotex dT30, Takara, Ohtsu, Japan). Northern blot analysis was performed by blot hybridization of $2 \mu \mathrm{g}$ poly $\left(\mathrm{A}^{+}\right)$RNA with the above lac $Z$ probe.

Antibodies. The primary antibodies were purchased as follows: mouse monoclonal antibodies against protein kinase $\mathrm{C}$ (PKC) (MC5) from Amersham (Buckinghamshire, UK) and against lacZ from Boehringer Mannheim (Mannheim, Germany), and rabbit polyclonal antibodies against PKC $\alpha$-isoform from Boehringer Mannheim and against lacZ from Cappel (Durham, NC); these antibodies were diluted at 1:100 for use. Mouse monoclonal antibody against $\mathrm{PKC}$ was reported to be reactive with only PKC $\alpha$-isoform (Osborne et al., 1992), but immunoreactivity detected by this antibody as well as rabbit polyclonal antibody against PKC $\alpha$-isoform is described as PKC immunoreactivity in this manuscript. Previously, polyclonal anti-mGluR6 rabbit IgG was generated in this laboratory (Nomura et al., 1994) and diluted at 1:250. Secondary antibodies were purchased as follows: Texas Red (TR)-X-conjugated goat IgGs against rabbit $\mathrm{IgG}$ and against mouse $\mathrm{IgG}$ from Molecular Probes (Eugene, OR), dichlorotriazinyl aminofluorescein (DTAF)-conjugated goat IgG against mouse $\mathrm{IgG}$ from Chemicon (Temecula, CA), and fluorescein isothiocyanate (FITC)-conjugated goat IgG against rabbit IgG from Cappel. These antibodies were used at a dilution of 1:200 Biotinylated goat $\mathrm{IgGs}$ against rabbit $\mathrm{IgG}$ and against mouse $\mathrm{IgG}$ were purchased from Vector Laboratories (Burlingame, CA). These antibodies were used at a dilution of 1:200-1:1000 and then reacted with FITCconjugated avidin (Vector) or TR-X-conjugated streptavidin (Molecular Probes) at a dilution of 1:1000.

Histochemistry and immunostaining. The animals used were heterozygous transgenic mice 1-4 months old, unless otherwise stated. After anesthesia with diethylether, an animal was perfused via the left ventricle with $0.01 \mathrm{M}$ PBS, $\mathrm{pH} 7.3$, followed by fixatives in PBS. Glutaraldehyde $(0.4 \%)$ was used for X-gal staining, and $4 \%$ formaldehyde was used for fluorescence immunostaining. Perfusion was omitted for very young pups, which were decapitated immediately after anesthesia. Eyes were enucleated and immersed in the same fixative solution for $10 \mathrm{~min}$. When lac Z immunoreactivity was examined, eyes were dissected at the limbus, and retinas were isolated mechanically and immersed in the fixative solution for another $2 \mathrm{hr}$. After fixation, whole eyes or isolated retinas were cryoprotected with $10 \%$ sucrose and then $15 \%$ sucrose for $10 \mathrm{~min}$, embedded in O.C.T. compound (Miles, Elkhart, IN), and frozen in liquid nitrogen. The samples were sectioned at $10 \mu \mathrm{m}$ on a cryostat at $-17^{\circ} \mathrm{C}$. Mounted sections were air-dried for 10-30 min and rinsed in PBS. X-gal staining was performed for $4-8 \mathrm{hr}$ in a staining solution $[1 \mathrm{mg} / \mathrm{ml} \mathrm{X-gal,}$ $17.5 \mathrm{mM} \mathrm{K} \mathrm{K}_{3} \mathrm{Fe}(\mathrm{CN})_{6}, 17.5 \mathrm{~mm} \mathrm{~K}_{4} \mathrm{Fe}(\mathrm{CN})_{6}, 1 \mathrm{mM} \mathrm{MgCl}_{2}$, and $0.2 \%$ Nonidet-40 in PBS] at $37^{\circ} \mathrm{C}$. For some samples counterstaining was performed with neutral red. For X-gal staining of the brain, mice were perfused and fixed with $0.4 \%$ glutaraldehyde in PBS. Whole brains were removed and immersed in the same fixative solution for another $30 \mathrm{~min}$. Then the brain was incubated with the X-gal reaction solution for 6-8 hr at $37^{\circ} \mathrm{C}$. In most cases $\mathrm{X}$-gal staining was observed externally, but in some cases with no such external staining, brains were cryoprotected as described above and embedded in O.C.T. compound. The frozen samples then were sectioned at $40-50 \mu \mathrm{m}$ thicknesses with a cryostat and mounted on slide glasses.

For immunofluorescence staining, mounted sections were rinsed, preincubated with $2 \%$ normal goat serum in PBS, and incubated overnight with the primary antibody at $4^{\circ} \mathrm{C}$. The sections were reacted with the secondary biotinylated antibody at room temperature for $1 \mathrm{hr}$ and then with the fluorochrome-conjugated secondary antibody and fluorochrome-avidin complex at room temperature for $30 \mathrm{~min}$. After final rinsing with PBS, the samples were coverslipped with a glycerol/PBS (1:1) solution containing $0.1 \%$ p-phenylenediamine (Sigma, St. Louis, MO), and the edge of the coverslip was sealed with nail enamel. Fluorescence immunoreactivity was viewed by confocal microscopy. For quantitative analysis of differently immunoreactive cells, the cell number was counted in a confocal image dissected at $1.2 \mu \mathrm{m}$ thicknesses.

Cell dissociation and immunostaining. Dissociated bipolar cells were prepared according to the procedures described previously (Ueda et al., 1992), with some modifications. Eyes from pups of postnatal days (PD) 12-20 were enucleated, and the sclera and choroid were peeled off. The retinas were isolated mechanically from the vitreous body and anterior segment and incubated in Hank's buffered saline solution containing papain (Roth, Carlsruhe, Germany; $50 \mathrm{mg} / 30 \mathrm{ml}$ ) and L-cysteine (Nakalai tesque, Kyoto, Japan; $15 \mathrm{mg} / 30 \mathrm{ml}$ ) under oxygenation with $\mathrm{O}_{2} / \mathrm{CO}_{2}$ (95:5) gas, $\mathrm{pH} 7.0$, for $40-50 \mathrm{~min}$ at $28^{\circ} \mathrm{C}$ in a swirling incubator. Retinas were rinsed three times with a normal extracellular solution (NES) containing (in mM) $130 \mathrm{NaCl}, 10 \mathrm{KCl}, 1 \mathrm{MgCl}_{2}, 2 \mathrm{CaCl}_{2}, 5 \mathrm{HEPES}$, and 10 glucose plus $0.1 \mathrm{mg} / \mathrm{ml}$ bovine serum albumin and $0.001 \%$ phenol red, adjusted to $\mathrm{pH} 7.3$ with $\mathrm{NaOH}$ and triturated with a blunt-tip pipette. The glass slide was attached with a silicone ring, coated with Concanavalin A (Wako Chemicals, Osaka, Japan), and filled with NES. Dissociated retinal cells were dispersed on a glass slide and stored for at least $1 \mathrm{hr}$ at $4^{\circ} \mathrm{C}$. Immunostaining of dissociated cells was performed as described for retinal sections except that each step was shortened as follows: 5-10 min in fixation, $10 \mathrm{~min}$ in blocking reaction, $30 \mathrm{~min}-1 \mathrm{hr}$ in primary antibody reaction, and $30 \mathrm{~min}$ in secondary antibody reaction.

\section{RESULTS}

\section{Generation of the mGluR6/lacZ transgenic mice}

To address whether the mGluR6 upstream sequence is capable of directing its expression in a cell-specific and developmentally regulated manner, we fused the $5^{\prime}$ flanking region of the mouse mGluR6 gene to the lac $Z$ reporter gene. The fusion gene consisted of the $9.5 \mathrm{kbp}$ mGluR6 upstream genomic fragment, starting from $49 \mathrm{bp}$ upstream of the mGluR6 translation initiation site; the $293 \mathrm{bp}$ fragment containing the translation initiation site of the $E$. coli gpt gene (Hall et al., 1983); the lacZ gene, starting from $25 \mathrm{bp}$ downstream of the $l a c Z$ translation initiation site; and two polyadenylation sites derived from the SV40 gene (Fig. 1A). The genomic sequence that covers the translation initiation site of mGluR6 and its upstream sequence is presented in Figure $1 B$. We recently have indicated that the human mGluR6 mRNA starts at 179 bp upstream from the translation initiation site with no intronic interruption at the $5^{\prime}$ untranslated region (Hashimoto et al., 1997). However, because the nucleotide sequences of the $5^{\prime}$ untranslated region and its upstream $5^{\prime}$ flanking region diverge 


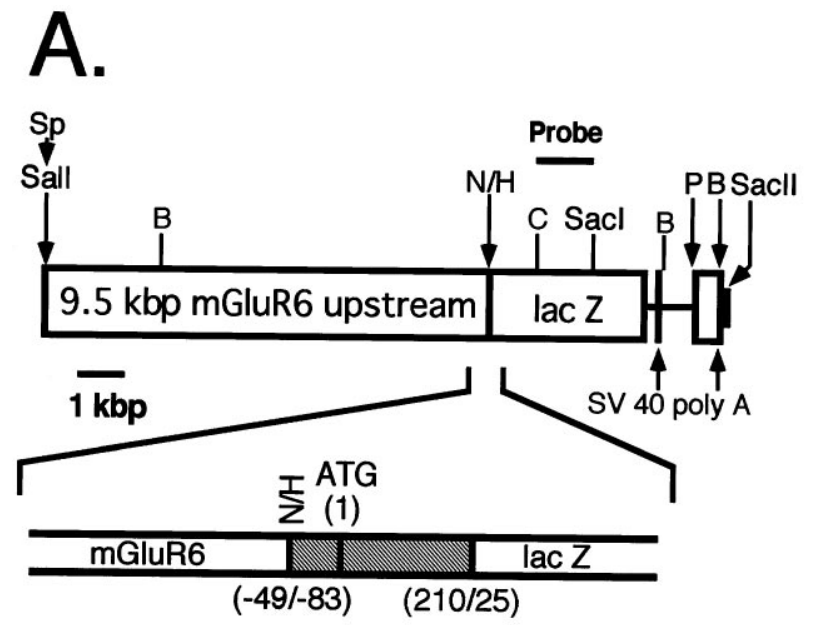

B.
C.

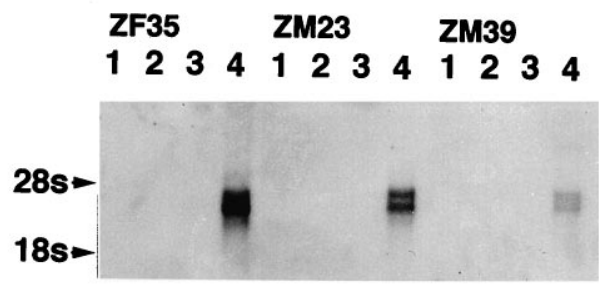

TCTAGACTGTAGCTCTGATTTTACAGCTGTCACAGACTCGTCCTACTAGCCAGAGGTTGG CTCAGGTAAGCACCACTGGGGAGGTAGCCTAGGGTGCGCTGGGGTGGGTCCAGAGGAAGA GCTGCCCAGAACTGTGGGGGAAGGAGCGGGACCGACCATCAACAGGGGGACTTTTCAGGG AGAATGAGÄGCAATCCTCTGGAGGCCTGGGAGAGGCTGCTGAGTTGCTGGTGCGCGAGTC ACCAACTTTTCCTGCGCTCTCGGTGTCCGGCCAGAATCCCGAAGTGGCAGCTGAGCACGG NaeI GGTGGCAGCTTCGTCCGCCGGCTCTCAAGGCGTCCCGGTAACTTCCTTTCCCGCAGTCCA GGAGCAGATGGGCGGCTCCGAGTGCTGCTGCTGTGGCTAGCCTGGTGGCTGTCGCAGGC

Figure 1. The MG6-Z transgene structure, the mouse mGluR6 genomic sequence around the potential transcription initiation site, and Northern blot analyses of transgenic mice. $A$, The MG6-Z transgene used for generation of transgenic mice was constructed from three different DNA fragments according to the procedures described under Materials and Methods. The restriction sites shown by arrows indicate the fusion sites; $S p, S p h \mathbf{I} ; N, N a e$; $H$, HindIII; P, PstI; B, BamHI. The SphI-NaeI fragment represents the mGluR6 upstream sequence. The HindIII-PstI fragment contains the gpt, trpS, lacZ, and SV40 sequences. The Pst $\mathrm{I}-$ Bam HI fragment encodes the SV40 sequence. The region around the translation initiation site of the transgene is expanded below the MG6-Z transgene; the shaded region indicates the gpt and trpS structures. The numbers shown below stand for nucleotide positions of the $5^{\prime}$ or $3^{\prime}$ termini of the fused genes. The $C l a \mathrm{I}(\mathrm{C})-\mathrm{Sac}$ I fragment was used as a labeled probe for Southern and Northern blot analyses. $B$, The nucleotide sequence around the potential transcription initiation site of the mouse mGluR6 gene is presented. The translation initiation site is boxed, and the NaeI site used for the transgene construction is indicated. The position corresponding to the transcription initiation site of the human mGluR6 gene (Hashimoto et al., 1997) is marked by an asterisk, and the position of the $5^{\prime}$ end of the rat mGluR6 cDNA clone containing the extreme 5' sequence (Nakajima et al., 1993) is shown by an arrowhead. It is noted that the nucleotide sequences compared are highly homologous between the mouse and rat counterparts but diverge between the mouse and human counterparts. $C$, Northern blot analysis of poly $\left(\mathrm{A}^{+}\right)$RNA $(2 \mu \mathrm{g})$ isolated from the cortex $($ lane 1), cerebellum (lane 2), brainstem (lane 3), and retina (lane 4) of the three transgenic mice. $18 S$ and $28 S$ are ribosomal RNAs used as a marker RNA.

considerably between the human and mouse mGluR6 genes, the transcription initiation site of the mouse mGluR6 gene could not be assigned definitely.

The fusion gene was microinjected into fertilized mouse eggs, which then were transferred to foster mothers. On blot hybridization analysis of tail DNAs, we identified 13 independent transgenic lines that passed their transgenes onto their offspring. All but three lines exhibited an X-gal-positive staining in the defined cell layers of the retina. However, because some of these transgenic mice also showed an X-gal staining in particular brain regions, depending on individual transgenic lines, we chose and characterized in more detail three male lines (ZM23, ZM39, and ZM41), in which $l a c Z$ was expressed restrictedly in the retina, and one female line (ZF35), in which lacZ was detected in the retina and a part of the amygdala. Blot hybridization analysis of tail
DNAs indicated that ZF35, ZM23, ZM39, and ZM41 possessed $\sim 7-8, \sim 5-6, \sim 1-2$, and $\sim 40-50$ copies of the lac $Z$ gene in the genomic DNA, respectively (data not shown). The tissue specificity of the lac $Z$ expression was analyzed by Northern blot hybridization of poly $\left(\mathrm{A}^{+}\right)$RNA of the retina, cerebral cortex, cerebellum, and brainstem isolated from these four transgenic animals (Fig. 1C). This analysis revealed that in the ZF35, ZM23, and ZM39 lines two species of lacZ mRNA, which probably were generated by different polyadenylations, were expressed selectively in the retina and in no other parts of the brain. The amount of the $L a c Z$ mRNA expressed approximately paralleled the number of the integrated $l a c Z$ genes in these transgenic lines. However, no appreciable lac $Z$ mRNA was detected in any parts of poly $\left(\mathrm{A}^{+}\right)$RNA in the ZM41 line despite an insertion of multiple copies of the lac $Z$ gene in this transgenic mouse. 

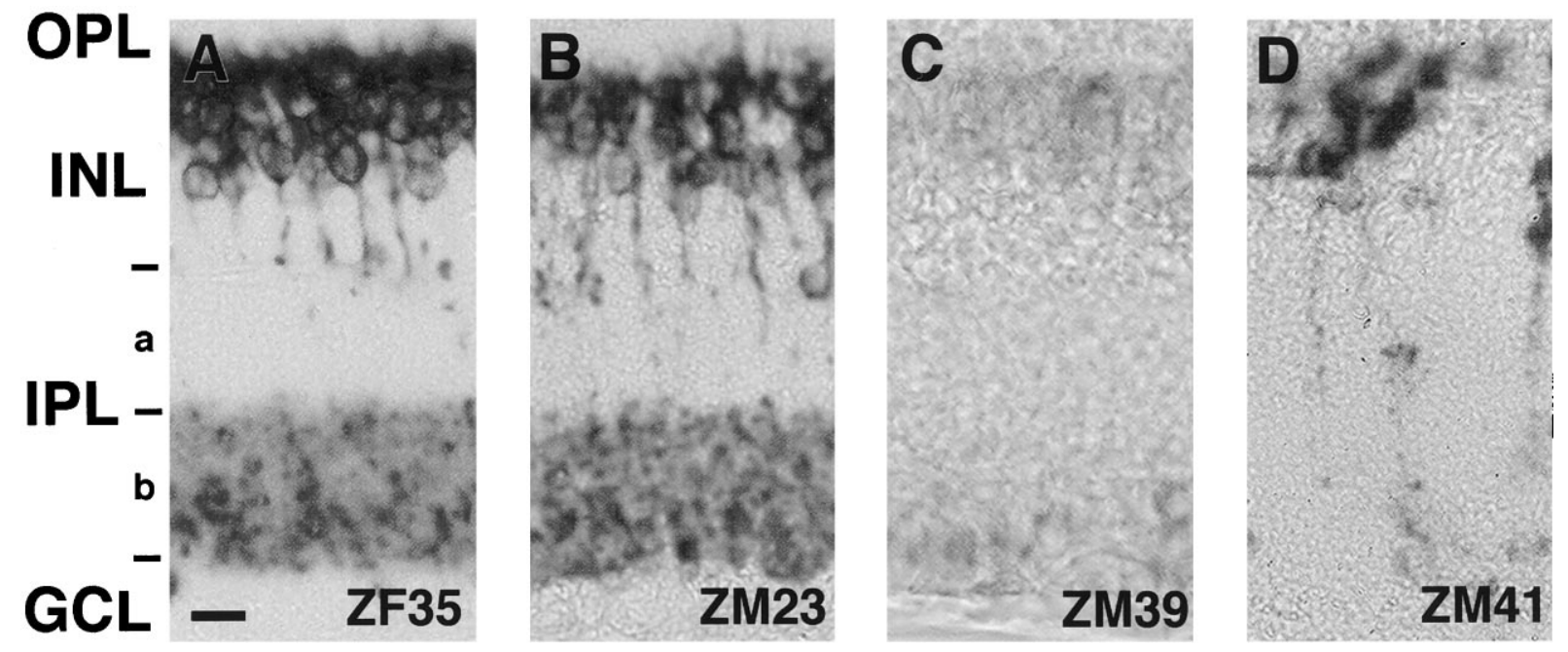

Figure 2. X-gal staining of transverse retinal sections of the four transgenic mice. The densities of the X-gal reaction product are different among the four transgenic lines, but the X-gal staining is commonly observed in the cell bodies at the outer portion of the INL and in the axon terminals at the inner portion of the IPL. $a$, Sublamina a; $b$, sublamina b. Scale bars in this figure and the subsequent figures, except for Figure 7 , represent $10 \mu \mathrm{m}$.

\section{LacZ expression pattern in retinal bipolar cells}

We first examined an $\mathrm{X}$-gal staining pattern in transverse retinal sections of the four transgenic lines (Fig. 2). The densities of the $\mathrm{X}$-gal reaction product were not identical among the four transgenic mice. ZF35 and ZM23 showed a strong and dense staining, whereas ZM39 was weak in X-gal staining. ZM41 exhibited a sparse and compartmentalized staining throughout the retinal section. The densities of the X-gal staining corresponded to expression levels of the lac $Z$ mRNA in the transgenic lines. The retina consists of several different cell layers: the outer nuclear layer (ONL), composed of photoreceptors; the inner nuclear layer (INL), consisting of bipolar, horizontal, and amacrine cells; and the ganglion cell layer (GCL), containing mostly ganglion cells. Photoreceptors, bipolar cells, and horizontal cells make synaptic connections in the outer plexiform layer (OPL), whereas bipolar, amacrine, and ganglion cells make contact in the inner plexiform layer (IPL). The ON-type and OFF-type bipolar cells seem to differ in stratification levels of their axon terminals in the IPL and probably are correlated to an inner (sublamina b) and outer (sublamina a) stratification of their axon terminals, respectively (Wässle and Boycott, 1991). Although the densities of the X-gal staining differed from one another, the spatial pattern of the staining was common among the four transgenic mice. In all transgenic lines, the X-gal-stained cell bodies were located at the outer portion of the INL, and the axonal extensions terminated at the inner portion (sublamina b) of the IPL (Fig. 2). Furthermore, the X-gal-stained axon terminals seemed to be separated into two levels in sublamina $\mathrm{b}$ of the IPL. Thus, lac $Z$ is expressed in a defined and common subset of bipolar cells in all transgenic mice. On X-gal staining in various brain regions, only ZF35 showed sparsely distributed X-gal staining cells in the amygdala (data not shown). Thus, this expression was thought to be ectopic, characteristic of the ZF35 transgenic line, and was not investigated further.

We also performed immunostaining of transverse sections of retina with anti-lac $Z$ antibody and examined an immunostaining pattern of lac $Z$ expression via confocal microscopy. The immunofluorescent patterns of the $l a c Z$ expression were identical with the X-gal staining patterns in all four transgenic mice (Fig. $3 A-D$ ). In these sections mGluR6 immunoreactivity also was examined by coimmunostaining with the mGluR6-specific antibody, and punctate mGluR6 immunoreactivity, like the wild-type mouse retina (Masu et al., 1995), was observed in the OPL of the retinal sections of the transgenic mice (Fig. $3 E-H$ ). Thus, the expression patterning of mGluR6 was not affected in any of the transgenic mice.

\section{Cell types expressing lacZ in the retina}

Rod bipolar cells have been shown to be labeled selectively with the antibody against PKC (Negishi et al., 1988). To investigate whether lac $Z$ is expressed in rod bipolar cells under the control of the $5^{\prime}$ flanking mGluR6 sequence and whether this expression also occurs in ON-type cone bipolar cells, we performed doubleimmunofluorescence staining with the PKC antibody and the lac $Z$ antibody. Because a nonspecific background staining inevitably was observed at the GCL when rabbit antibodies were used (Fig. 4), we performed double-immunofluorescence staining with two different combinations: polyclonal anti-lac $Z$ rabbit IgG and monoclonal anti-PKC mouse IgG (Fig. 4A,C,E-G), and monoclonal anti-lac $Z$ mouse $\mathrm{IgG}$ and polyclonal anti-PKC rabbit IgG (Fig. $4 B, D)$. In both combinations the cell bodies of PKCimmunoreactive rod bipolar cells were located at the outer border of the INL, and their axons descended toward the inner border of the IPL close to the GCL (Fig. 4). These rod bipolar cells always showed lacZ immunoreactivity (Fig. 4). A subpopulation of amacrine cells is known to be PKC-immunoreactive (Negishi et al., 1988), and PKC-immunoreactive amacrine cells were identified by their location in the inner part of the INL and were expectedly immunonegative with the lac $Z$ antibody (arrows in Fig. 4A,B).

Remarkably, a large number of PKC-negative but lacZ-positive cells were detected in all four transgenic lines. Their cell bodies were located at the position similar or close to the rod bipolar cell bodies in the outer part of the INL, and their axon terminals resided in the outer half of sublamina b of the IPL (Fig. 4). This characteristic spatial pattern of both lacZ-positive/PKC-positive and lacZ-positive/PKC-negative cells was commonly observed in the four transgenic lines, although expression levels of lac $Z$ were different among them (Fig. 4A,E-G). Recently, Euler et al. (1996) identified a population of L-AP4-responsive ON-type cone bipolar cells by combining electrophysiological recordings and intracellu- 

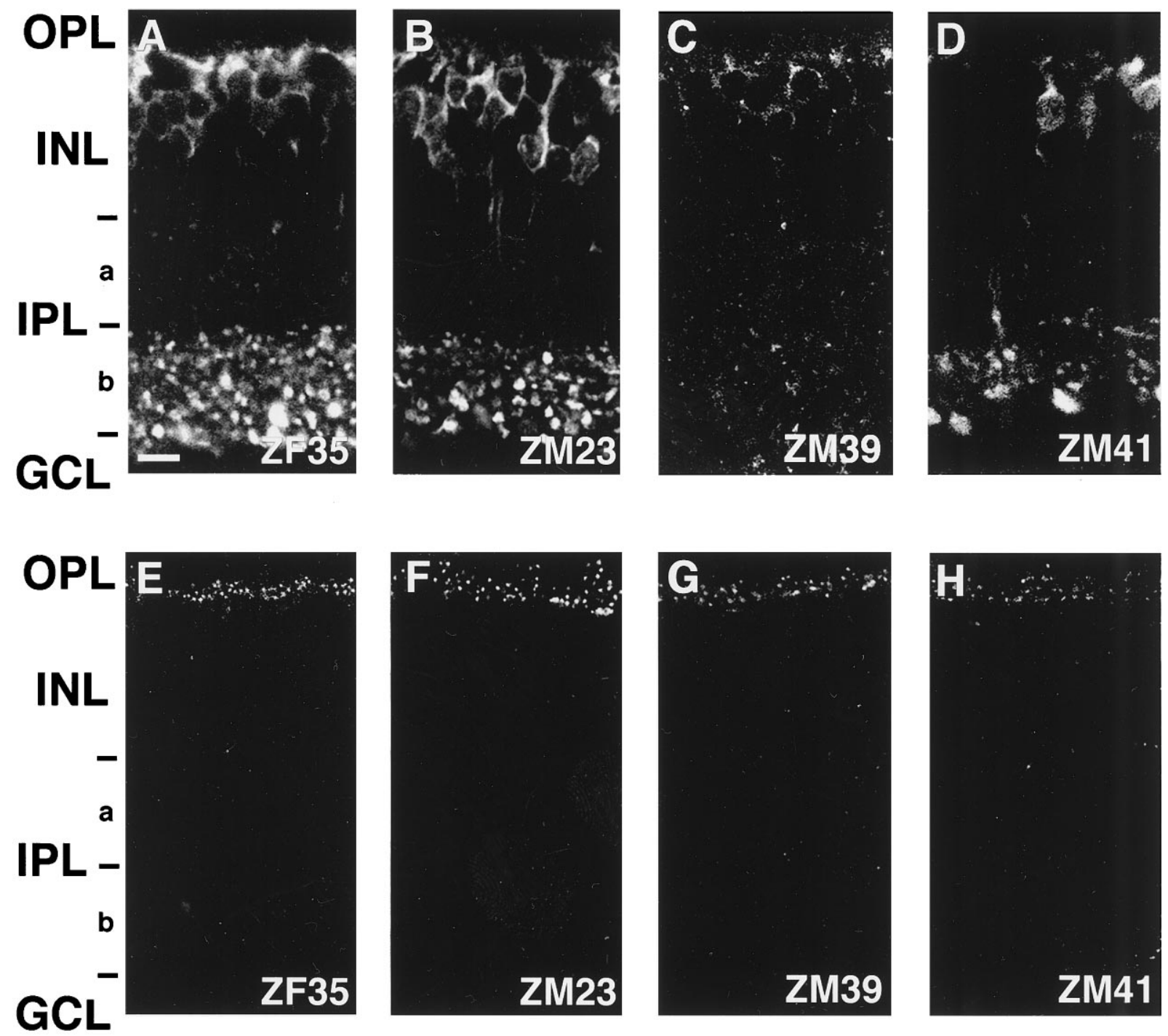

Figure 3. Double-immunofluorescence staining of lac $Z$ and mGluR6 immunoreactivities in transverse retinal sections of the four transgenic mice. The densities and patterns of lacZ immunoreactivity $(A-D)$ are identical to those of the X-gal staining indicated in Figure 2 . Punctate mGluR6 immunoreactivity $(E-H)$ is seen only at the $O P L$ and is not affected by different expression levels of lac $Z$ in the four transgenic lines.

lar staining with Lucifer yellow in a rat retinal slice preparation and reported that ON-type cone bipolar cells, classified as types 6, 7 , and 8 , have cell bodies close to or near the rod bipolar cells and terminate their axons at sublamina b. Notably, the spatial pattern of these ON-type cone bipolar cells was consistent with that of the lacZ-positive/PKC-negative cells, strongly suggesting that the lac $Z$ expression is directed under the control of the mGluR6 promoter in not only rod bipolar cells but also ON-type cone bipolar cells.

On the basis of the above finding, we estimated the cell number of different immunoreactive cells from transverse retinal sections of the adult ZF35 transgenic mice (2-4 months). Cells were counted from 19 confocal images without taking into consideration the locations of retinal sections. The sums of the counted cells were as follows: lacZ-positive cells, 686; PKC-positive bipolar cells, 311; PKC-positive amacrine cells, 51. The numbers of lacZpositive/PKC-positive bipolar cells, the lacZ-positive/PKCnegative bipolar cells, and the PKC-positive amacrine cells were 311,375 , and 51 , corresponding to relative ratios of 1.0:1.21:0.16.
This finding indicates that ON-type cone bipolar cells exist as a large population comparable to rod bipolar cells.

\section{Double-immunofluorescence staining in dissociated bipolar cells}

To characterize cell types expressing lac $Z$ further, we performed double immunostaining of dissociated bipolar cells. The retina of the ZF35 mouse was dissociated by enzymatic digestion, and dissociated cells were double-immunostained with the $l a c Z$ and PKC antibodies. In a dissociated cell preparation, there were many lacZ-positive/PKC-positive cells with a typical rod bipolar cell morphology with a long axonal extension (Fig. 5). In addition, a large number of $l a c Z$-positive/PKC-negative cells were observed (Fig. 5). Some of them could not be distinguished as either nonspecifically stained cell debris or enzymatically damaged lacZpositive/PKC-negative cells (Fig. 5A,B). However, many other lacZ-positive/PKC-negative cells showed a cell shape with a short dendritic or axonal process (arrows in Fig. $5 B$ and Fig. $5 C, D$ ). Furthermore, consistent with the double-immunofluorescence 

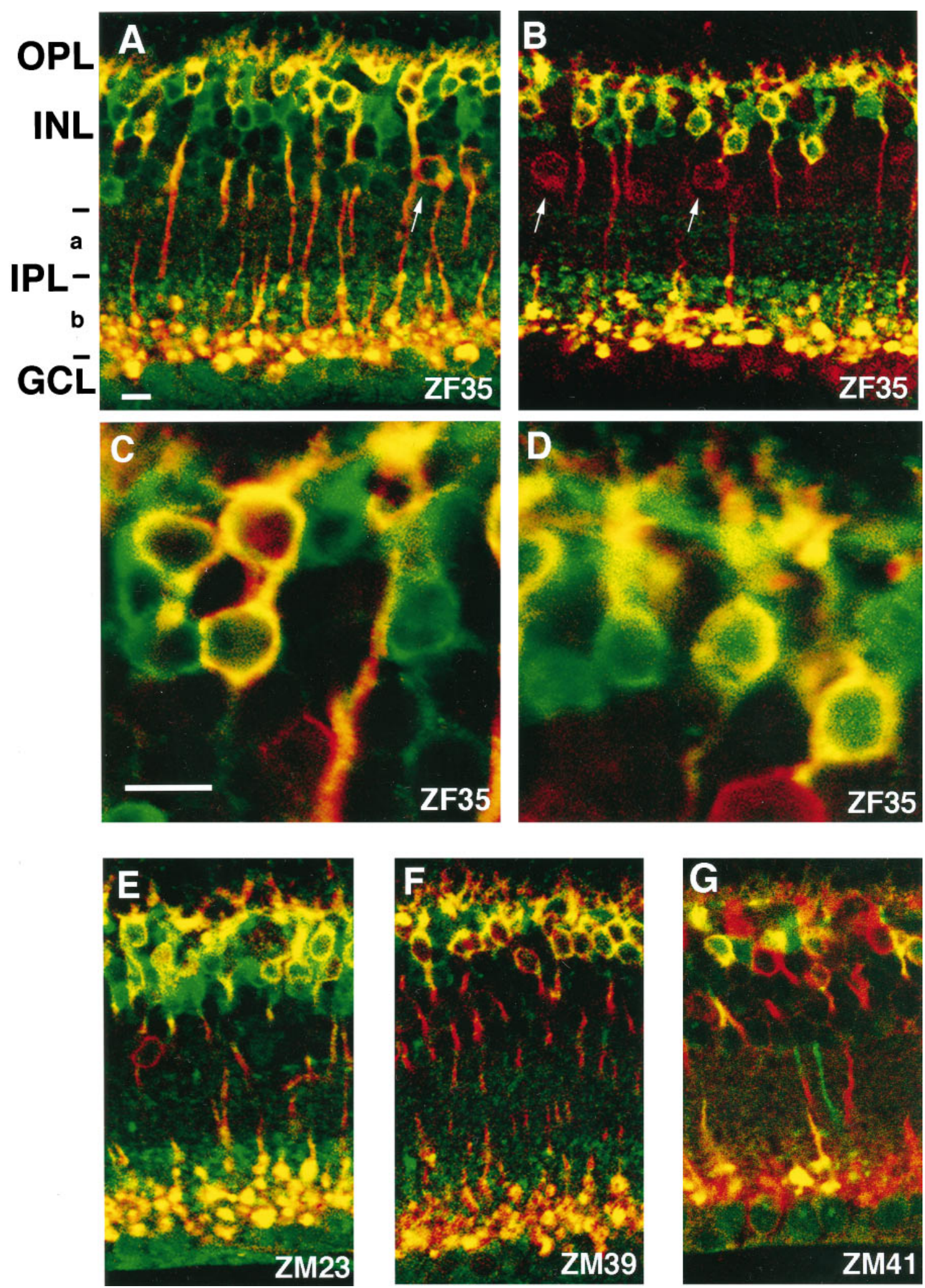

Figure 4. Double-immunofluorescence staining of lac $Z$ and PKC immunoreactivities in transverse retinal sections of the four transgenic mice. Double-immunofluorescence staining of the lac $Z$ and PKC immunoreactivities was performed by two different combinations of primary antibodies against PKC (red) and lacZ ( green): polyclonal anti-lacZ rabbit IgG and monoclonal anti-PKC mouse $\operatorname{IgG}(A, C, E-G)$ and monoclonal anti-lacZ mouse $\operatorname{IgG}$ and polyclonal anti-PKC rabbit $\operatorname{IgG}(B, D)$. More magnified views showing immunoreactive cell bodies are indicated in $C$ and $D$. Two types of cell bodies showing lacZ-positive/PKC-positive immunoreactivity (yellow) and lacZ-positive/PKC-negative immunoreactivity (green) are seen clearly in retinal sections of all four transgenic mice. The axon terminals of lacZ-positive/PKC-positive rod bipolar cells reside in the innermost part of the IPL close to the $G C L$, whereas those of lacZ-positive/PKC-negative bipolar cells reside in the outer half of sublamina b (b) of the IPL. LacZ-negative/PKC-positive amacrine cells also are seen, as indicated by arrows. Immunoreactivity seen at the $G C L$ in all preparations is noted as a nonspecific immunoreaction with rabbit $\operatorname{IgG}$, because this immunoreactivity is seen as dependent on the use of rabbit IgG but independent of immunostaining with either lacZ or PKC. 


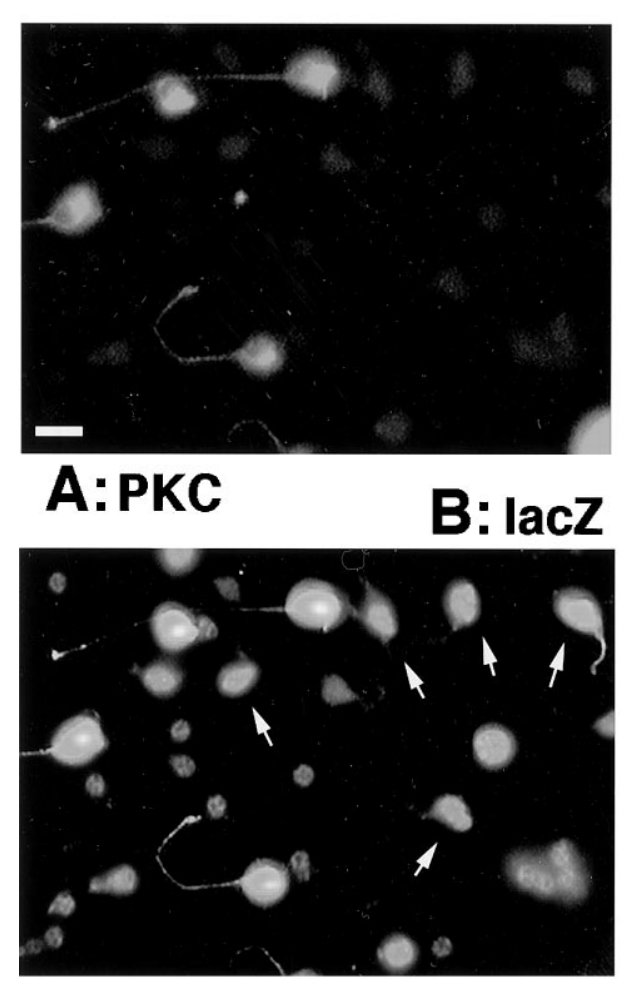

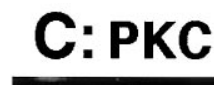

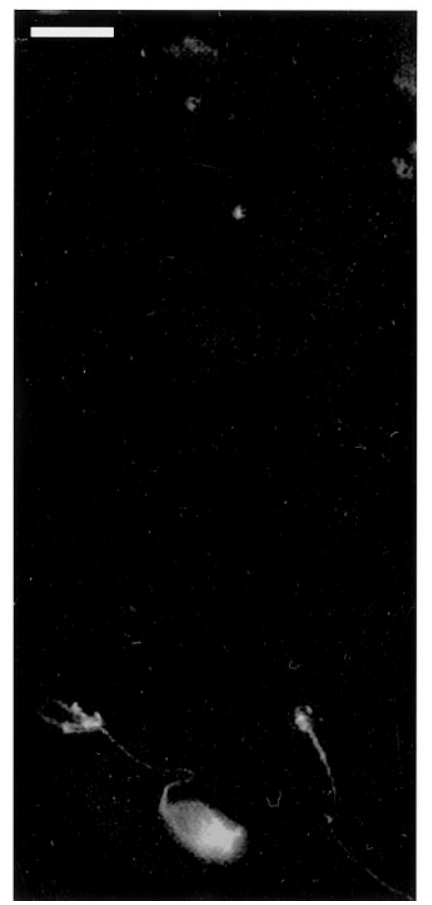

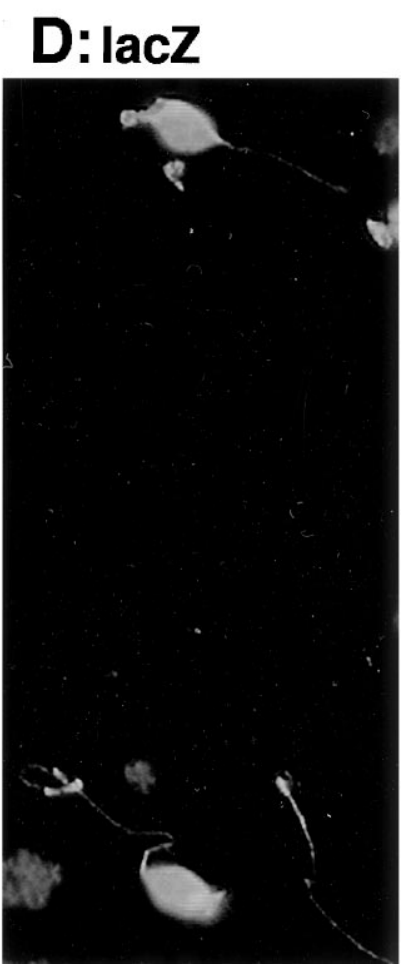

Figure 5. Double-immunofluorescence staining of dissociated bipolar cells of the ZF35 transgenic mouse by anti-lac $Z$ and anti-PKC. $A, B$, There are comparable numbers of lacZ-positive/PKC-positive and lacZ-positive/PKC-negative cells seen in a densely dispersed preparation. Arrows indicate lacZ-positive/PKC-negative cells showing a cell shape with a dendritic or axonal process. $C, D$, Two cell types showing a more intact morphology are indicated.
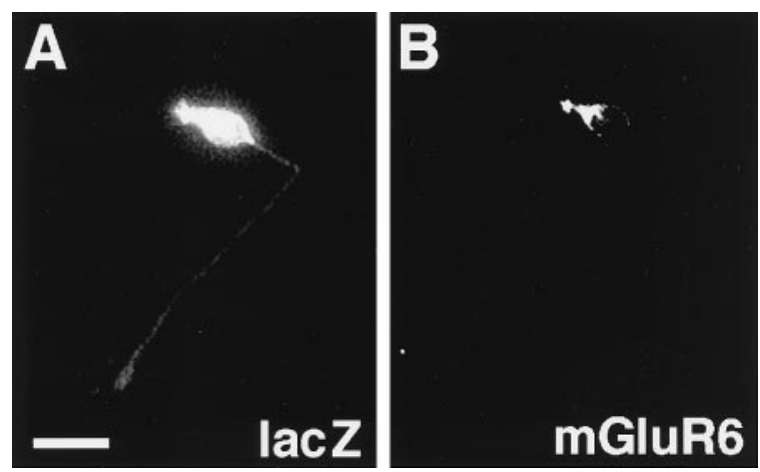

Figure 6. Colocalization of lacZ and mGluR6 immunoreactivities in a single cell. A dissociated bipolar cell derived from the ZF35 mouse on PD15 was double-immunostained with anti-lacZ $(A)$ and anti-mGluR6 $(B)$ antibodies. Intense mGluR6 immunoreactivity is seen on a dendritic tip of a lacZ-positive dissociated bipolar cell.

staining of a retinal section, lacZ-positive/PKC-negative cells existed in comparable numbers to the lac $Z$-positive/PKC-positive rod bipolar cells. This finding crucially demonstrates that a subpopulation of lacZ-expressing bipolar cells is PKC-negative.

We also confirmed coexpression of mGluR6 and lac $Z$ in a single cell by double immunostaining of dissociated bipolar cells with the lac $Z$ and mGluR6 antibodies. As reported previously (Nomura et al., 1994), mGluR6 immunoreactivity was confined to the dendritic site of the bipolar cell (Fig. 6). Furthermore, all intact mGluR6-immunoreactive cells were found to be lacZimmunoreactive in a dissociated cell preparation. It remained, however, to be distinguished whether these mGluR6/lacZ-positive cells were rod bipolar cells or ON-type cone bipolar cells. Because cone bipolar cells are more fragile than rod bipolar cells during cell dissociation, most of the mGluR6/lacZ-positive cells observed probably represent rod bipolar cells.

\section{LacZ expression during retinal development}

The expression of mGluR6 initiates and develops during the neonatal period in accordance with an orderly layered retinal cell arrangement and synaptic connections of bipolar cells (Nomura et al., 1994). We investigated ontogeny of the lac $Z$ expression during retinal development in the ZF35 transgenic line by both X-gal staining and double-immunofluorescence lacZ/mGluR6 staining. In X-gal staining the $\mathrm{X}$-gal reaction product was not detected on PD5, when the retina consisted of the differentiated GCL and the undifferentiated ventricular cells (Fig. 7A). On PD6, the ventricular cells developed into the immature INL and ONL, and a sparse X-gal staining appeared in the INL and IPL (Fig. 7B). On PD7, the X-gal staining became denser and more uniform at the outer portion of the INL and the inner half of the IPL (Fig. $7 C$ ). Interestingly, the lac $Z$ expression was not detected at the peripheral area of the retina on PD7 (Fig. 7D). At this stage the graded appearance of mGluR6 immunoreactivity was confirmed by mGluR6 immunostaining of a retinal section of the wild-type mice (data not shown). The observed spatial difference of the mGluR6 promoter function coincides with a delayed cellular development at the periphery of the retina (Young, 1985). On PD13, the X-gal staining extended to the peripheral retina near the ora serrata, thus becoming a mature pattern of lac $Z$ expression (Fig. $7 E$ ).

The developmental regulation of lac $Z$ expression also was examined by double-immunofluorescence staining with the $l a c Z$ and mGluR6 antibodies. On PD5, neither lacZ nor mGluR6 was detected (data not shown). On PD7, both mGluR6 and lacZ 
Figure 7. X-gal staining in developing retinas. X-gal staining was performed with transverse sections of developing retinas of the ZF35 mice. Retinas were counterstained with neutral red. Both scale bars represent $50 \mu \mathrm{m}$. $A$, The PD5 retina consists of the $G C L$ and undifferentiated ventricular cells $(V C)$ and shows no X-gal staining. $B$, On $P D 6$, the ventricular cells develop into the $O N L$ and $I N L$, divided by the $O P L$. An uneven X-gal staining starts in the middle of the INL and an inner part of the IPL. $C, D$, The $P D 7$ retina shows an $\mathrm{X}$-gal staining, but this staining is restricted to the central part of the retina. E, On $P D 13$, an X-gal staining spreads close to the ora serrata.

G
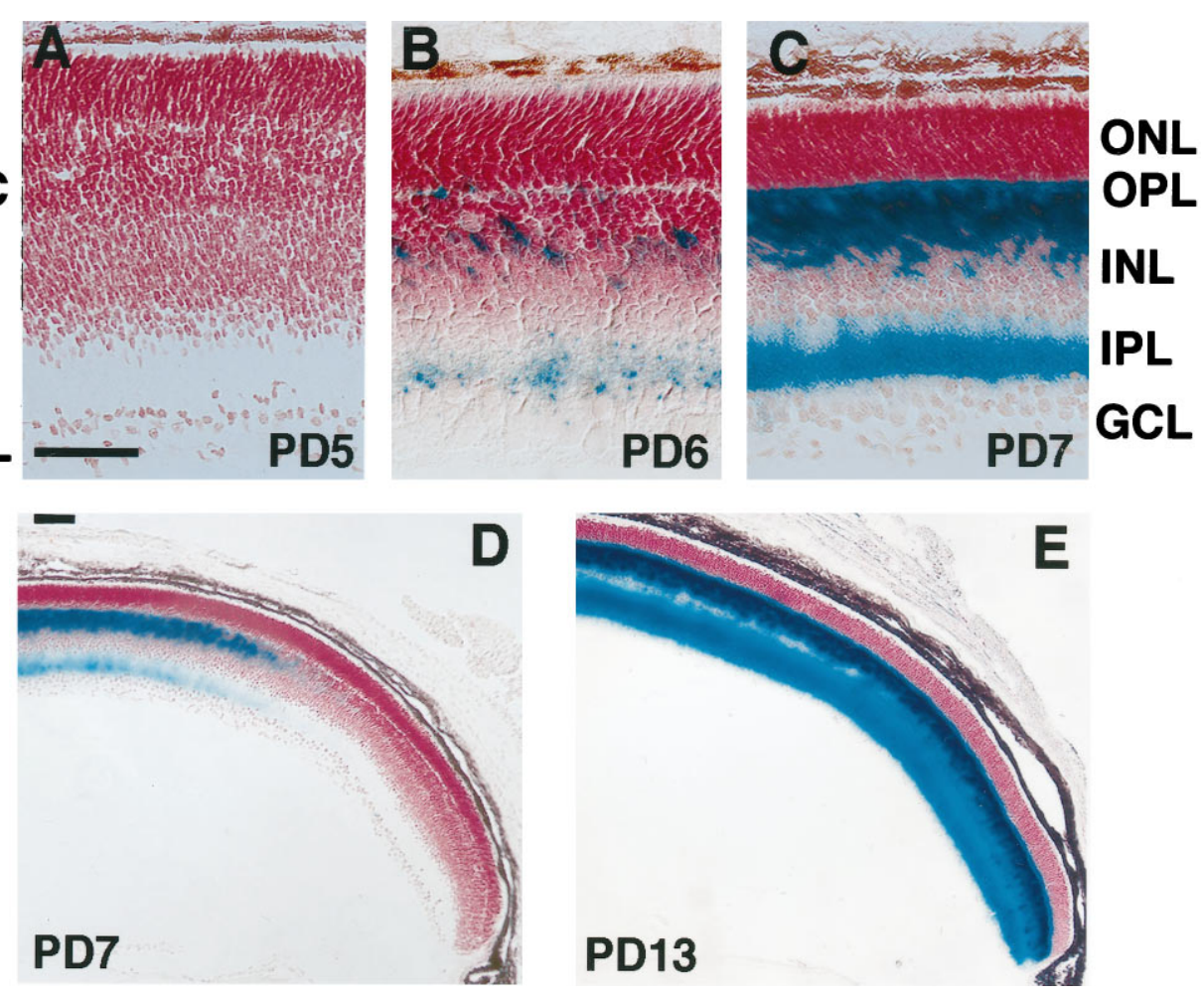

PD13

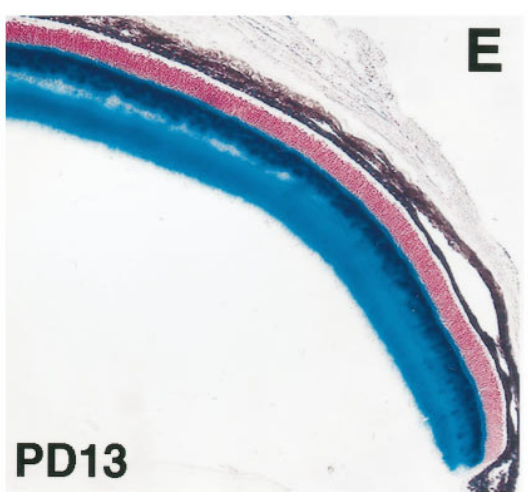

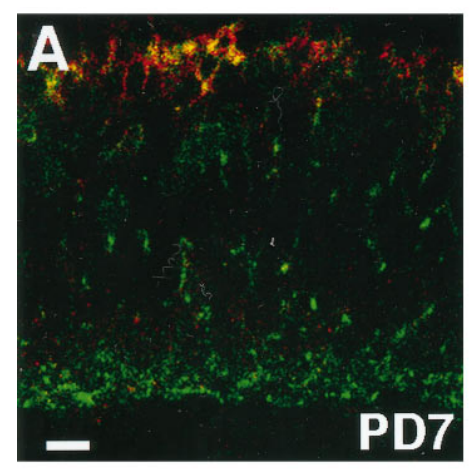
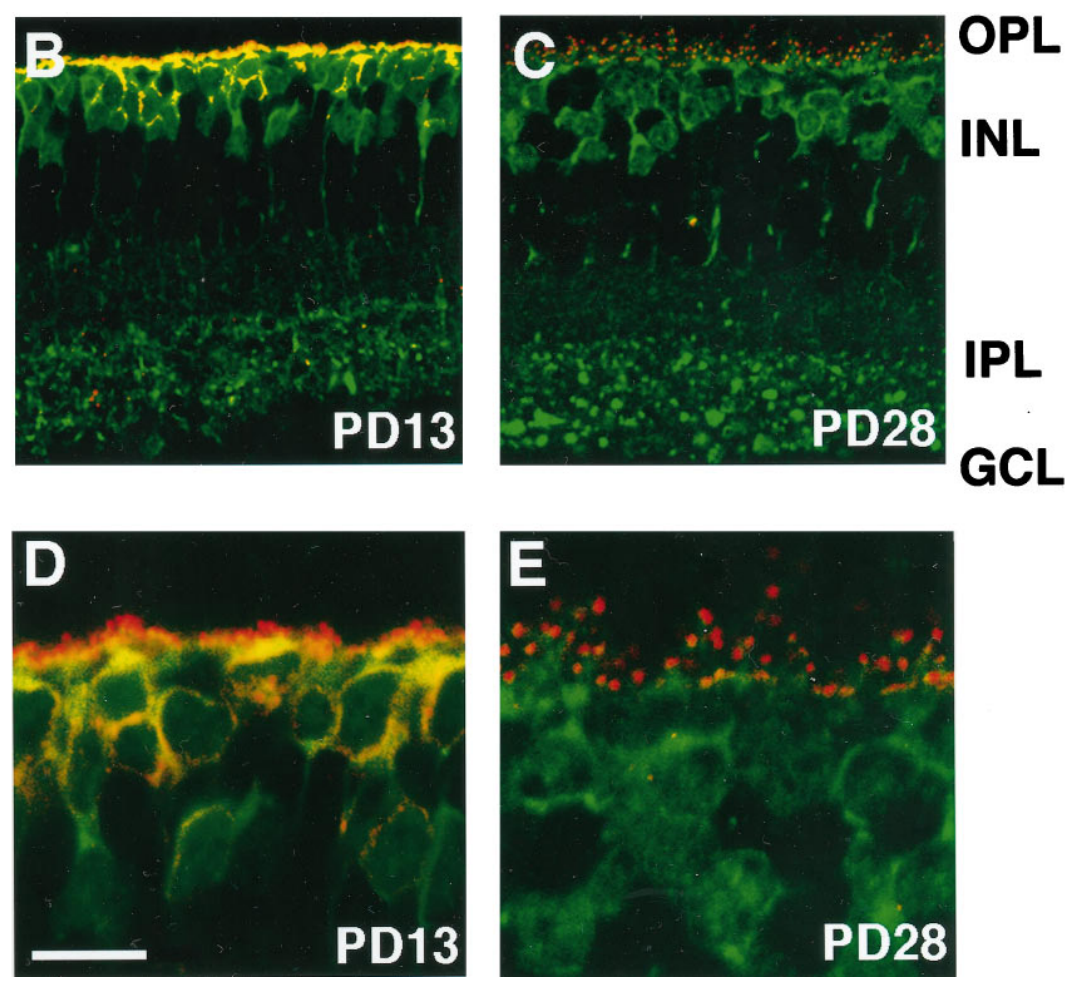

Figure 8. Double-immunofluorescence staining of $l a c Z$ and mGluR6 immunoreactivities in developing retinas of the ZF35 mice. $A$, The $P D 7$ retina shows weak and diffuse fluorescence for both mGluR6 and lacZ. B, D, On PD13, both lacZ and mGluR6 immunoreactivities are intensified. mGluR6 immunoreactivity is still observed in the cell bodies but gradually moves to the dendritic sides. $C, E$, On PD28, lac $Z$ immunoreactivity is unchanged, but mGluR6 immunoreactivity is concentrated at the tips of the dendrites. More magnified views of $B$ and $C$ are shown in $D$ and $E$, respectively.

immunoreactivities were observed faintly and diffusely at the cell body in the INL (Fig. 8A). In addition, axon terminals were also lacZ-positive. On PD13, both immunoreactivities became more manifested (Fig. 8B), and as reported previously (Nomura et al.,
1994), mGluR6 immunoreactivity still was observed diffusely in the cell bodies (Fig. 8D). On PD28, an immunofluorescent pattern of $l a c Z$ did not change with a diffuse staining throughout the cell body, dendrites, and axons (Fig. $8 C$ ), but mGluR6 immuno- 
reactivity was concentrated at the dendritic terminals in the OPL (Fig. $8 E$ ). Therefore, the ontogeny analysis explicitly demonstrates that the lac $Z$ expression is regulated temporally in a manner similar to the mGluR6 expression.

\section{DISCUSSION}

We have investigated the spatial and temporal expression patterns of the $l a c Z$ reporter gene under the regulation of $9.5 \mathrm{kbp}$ of the mouse mGluR6 5' upstream sequence. The results of this study have demonstrated that the $5^{\prime}$ flanking region of the mGluR6 gene encodes the sequence determinant that is necessary and sufficient for the cell-specific and developmentally regulated expression of the mGluR6 gene. First, although many of the transgenic lines were positive in the lac $Z$ expression in the brain, these expressions varied in the brain regions, depending on individual transgenic lines. In contrast, they constantly showed the lac $Z$ expression in the retinal bipolar cells. Furthermore, three transgenic lines exhibited a restricted lac $Z$ expression in retinal bipolar cells. Second, in a detailed characterization of the lac $Z$ expression in retinal sections of the four transgenic lines, the lac $Z$ expression always was observed in rod bipolar cells. Furthermore, in a dissociated bipolar cell preparation, the PKC-immunoreactive bipolar cells were lacZ-positive, with no exceptions. Third, the temporospatial pattern of the lac $Z$ expression agreed with that of the mGluR6 expression during retinal development.

In contrast to a wide distribution of the mRNAs for other mGluR subtypes in various brain regions (Nakanishi, 1994), the mGluR6 mRNA is expressed selectively in retinal bipolar cells (Nakajima et al., 1993). We recently have determined the whole nucleotide sequence of the human mGluR6 gene, consisting of $16742 \mathrm{bp}$ and its $5^{\prime}$ and $3^{\prime}$ flanking regions, and have indicated that the transcription initiation starts at $179 \mathrm{bp}$ upstream from the translation initiation site with no intronic interruption at the $5^{\prime}$ untranslated region of this mRNA (Hashimoto et al., 1997). Thus, analogous to the human mGluR6 gene, the $9.5 \mathrm{kbp} \mathrm{5'} \mathrm{flanking}$ fragment used in this study mostly likely possesses the transcription initiation site of the mouse mGluR6 gene, and this upstream region, as demonstrated in this study, is necessary and sufficient for the cell-specific and developmentally regulated expression of the mGluR6 gene. Another interesting finding is that the mGluR6 gene-promoted lac $Z$ expression, like the mGluR6 expression, is initiated and developed in accordance with the differentiation of bipolar cells, suggesting that the promoter function of the mGluR6 gene is tightly related to a genetic program of bipolar cell differentiation. Thus, a further dissection of the mGluR6 promoter region and a possible identification of regulatory factors for this expression would be interesting for understanding the mechanisms of retinal cell differentiation.

The role of mGluR6 in synaptic transmission from photoreceptors to rod bipolar cells was established by a number of previous studies. mGluR6 shows an agonist profile consistent with the property reported for the mGluR in ON-type bipolar cells (Nakajima et al., 1993). In situ hybridization signals of mGluR6 mRNA are restricted to the INL (Nakajima et al., 1993), and mGluR6 immunoreactivity is confined to the postsynaptic dendritic tips of rod bipolar cells (Nomura et al., 1994). Furthermore, the elimination of mGluR6 expression by gene targeting abolishes ON responses recorded from optic tract terminals (Masu et al., 1995). The evidence from knock-out experiments thus strongly suggests that both rod bipolar cells and ON-type cone bipolar cells express the mGluR6 receptor responsible for ON responses in these two systems. However, the mGluR6 deficiency, although severely impairing, still retains pupillary responses to high light intensities and the ability to drive optokinetic nystagmus in response to high visual contrasts (Iwakabe et al., 1997). A possible explanation for this observation is that crossover from the OFF pathway to the ON pathway may be capable of inducing pupillary responses and optokinetic reflex, although ON responses in both the rod and cone systems are defective in mGluR6 knock-out mice. Alternatively, a different L-AP4-responsive mGluR may mediate ON responses in the cone system. The retina, in fact, expresses four different L-AP4-responsive mGluR subtypes (Akazawa et el., 1994; Duvoisin et al., 1995). However, our recent study has indicated that all but mGluR6 are subcellularly located at the IPL and not at the OPL (our unpublished observation). Recently, Euler and Wässle (1995) characterized in detail the positions of the soma and the branching pattern and stratification levels of axon terminals of rat bipolar cells and classified bipolar cells into nine different types of cone bipolar cells and one type of rod bipolar cell. In a combination of the cell identification and wholecell recordings in a rat retinal slice preparation, Eular et al. (1996) reported that L-AP4 elicits ON-type current responses in cone bipolar cells with axons stratifying in the inner part of the IPL, thus indicating that these cells represent ON-type cone bipolar cells. Remarkably, the localization of the lacZ-positive/PKCnegative cells in transgenic mice precisely corresponds to that of the L-AP4-responsive ON-type cone bipolar cells. Furthermore, a large number of the lacZ-positive/PKC-negative cells, as comparable to that of rod bipolar cells, exist in both retinal section and dissociated retinal cells. Supporting this observation, Duvoisin and Vardi (1996) and Vardi and Morigiwa (1997) recently have reported that mGluR6 immunostaining is highly localized to dendritic tips of cone bipolar cells in the OPL of the human and rat, respectively. Taken altogether, the present study strongly indicates that the mGluR6 5' upstream sequence is capable of directing the expression of mGluR6, which is responsible for ON responses in both the rod and cone systems.

\section{REFERENCES}

Akazawa C, Ohishi H, Nakajima Y, Okamoto N, Shigemoto R, Nakanishi S, Mizuno N (1994) Expression of mRNAs of L-AP4-sensitive metabotropic glutamate receptors (mGluR4, mGluR6, mGluR7) in the rat retina. Neurosci Lett 171:52-54.

Daw NW, Jensen RJ, Brunken WJ (1990) Rod pathways in mammalian retinae. Trends Neurosci 13:110-115.

de la Villa P, Kurahashi T, Kaneko A (1995) L-Glutamate-induced responses and cGMP-activated channels in three subtypes of retinal bipolar cells dissociated from the cat. J Neurosci 15:3571-3582.

Dowling JE (1987) The retina: an approachable part of the brain. Cambridge, MA: Belknap, Harvard UP.

Duvoisin RM, Vardi N (1996) The mGluR6 L-AP4 receptor is expressed in both rod and cone ON bipolar cells in primate retina. Soc Neurosci Abstr 22:347.1.

Duvoisin RM, Zhang C, Ramonell K (1995) A novel metabotropic glutamate receptor expressed in the retina and olfactory bulb. J Neurosci 15:3075-3083.

Euler T, Wässle H (1995) Immunocytochemical identification of cone bipolar cells in the rat retina. J Comp Neurol 361:461-478.

Euler T, Schneider H, Wässle H (1996) Glutamate responses of bipolar cells in a slice preparation of the retina. J Neurosci 16:2934-2944.

Hall CV, Jacob PE, Ringold GM, Lee F (1983) Expression and regulation of Escherichia coli lac Z gene fusions in mammalian retina. J Mol Appl Genet 2:101-109.

Hashimoto T, Inazawa J, Okamoto N, Tagawa Y, Bessho Y, Honda Y, Nakanishi S (1997) The nucleotide sequence and chromosomal localization of the gene for human metabotropic glutamate receptor subtype 6. Eur J Neursci, in press.

Iwakabe H, Katsuura G, Ishibashi C, Nakanishi S (1997) Impairment of 
pupillary responses and optokinetic nystagmus in the mGluR6-deficient mouse. Neuropharmacology, in press.

Masu M, Iwakabe H, Tagawa Y, Miyoshi T, Yamashita M, Fukuda Y, Sasaki H, Hiroi K, Nakamura Y, Shigemoto R, Takada M, Nakamura K, Nakao K, Katsuki M, Nakanishi S (1995) Specific deficit of the ON response in visual transmission by targeted disruption of the mGluR6 gene. Cell 80:757-765.

Miller RF, Slaughter MM (1986) Excitatory amino acid receptors of the retina: diversity of subtypes and conductance mechanisms. Trends Neurosci 9:211-218.

Nakajima Y, Iwakabe H, Akazawa C, Nawa H, Shigemoto R, Mizuno N, Nakanishi S (1993) Molecular characterization of a novel retinal metabotropic glutamate receptor mGluR6 with a high agonist selectivity for L-2-amino-phosphonobutyrate. J Biol Chem 268:11868-11873.

Nakanishi S (1994) Metabotropic glutamate receptors: synaptic transmission, modulation, and plasticity. Neuron 13:1031-1037.

Nakanishi S (1995) Second-order neurones and receptor mechanisms in visual- and olfactory-information processing. Trends Neurosci 18:359-364.

Nawy S, Jahr CE (1990) Suppression by glutamate of cGMP-activated conductance in retinal bipolar cells. Nature 346:269-271.

Nawy S, Jahr CE (1991) cGMP-gated conductance in retinal bipolar cells is suppressed by the photoreceptor transmitter. Neuron 7:677-683.

Negishi K, Kato S, Teranishi T (1988) Dopamine cells and rod bipolar cells contain protein kinase C-like immunoreactivity in some vertebrate retinas. Neurosci Lett 94:247-252.

Nomura A, Shigemoto R, Nakamura Y, Okamoto N, Mizuno N, Nakanishi S (1994) Developmentally regulated postsynaptic localization of a metabotropic glutamate receptor in rat rod bipolar cells. Cell 77:361-369.

Osborne NN, Barnett NL, Morris NJ, Huang FL (1992) The occurrence of three isoenzymes of protein kinase $C(\alpha, \beta$ and $\gamma)$ in retinas of different species. Brain Res 570:161-166.

Schiller PH (1992) The ON and OFF channels of the visual system. Trends Neurosci 15:86-92.

Seed B (1987) An LFA-3 cDNA encodes a phospholipid-linked membrane protein homologous to its receptor CD2. Nature 329:840-842.

Shiells R (1994) Glutamate receptors for signal amplification. Curr Biol 4:917-918.

Shiells RA, Falk G (1990) Glutamate receptors of rod bipolar cells are linked to a cyclic GMP cascade via a G-protein. Proc R Soc Lond [Biol] 242:91-94.

Slaughter ML, Miller RF (1981) 2-Amino-4-phosphonobutyric acid: a new pharmacological tool for retina research. Science 211:182-185.

Ueda Y, Kaneko A, Kaneda M (1992) Voltage-dependent ionic currents in solitary horizontal cells isolated from cat retina. J Neurophysiol 68:1143-1150.

Vardi N, Morigiwa K (1997) ON cone bipolar cells in rat express the metabotropic receptor mGluR6. Vis Neurosci, in press.

Wässle H, Boycott BB (1991) Functional architecture of the mammalian retina. Physiol Rev 71:447-480.

Yamashita M, Wässle H (1991) Responses of rod bipolar cells isolated from the rat retina to the glutamate agonist 2-amino-4phosphonobutyric acid (APB). J Neurosci 11:2372-2382.

Young RW (1985) Cell differentiation in the retina of the mouse. Anat Rec 212:199-205. 